\title{
A METODOLOGIA DE KRISTIANSEN E INDARTI PARA IDENTIFICAR INTENÇÃO EMPREENDEDORA EM ESTUDANTES DE ENSINO SUPERIOR: COMPARANDO RESULTADOS OBTIDOS NA NORUEGA, INDONÉSIA E ALAGOAS. ${ }^{1}$
}

\author{
THE KRISTIANSEN'S AND INDARTI METHODOLOGY TO IDENTIFY \\ ENTREPRENEURIAL INTENTION IN HIGHER EDUCATION STUDENTS: \\ COMPARING OUTCOMES IN NORWAY, INDONESIA AND ALAGOAS.
}

\author{
Thiago Cavalcante Nascimento ${ }^{2}$ \\ Anderson de Barros Dantas ${ }^{3}$ \\ Paulo da Cruz Freire dos Santos ${ }^{4}$ \\ Manoel Veras ${ }^{5}$ \\ Antonio Gil da Costa Junior ${ }^{6}$
}

\begin{abstract}
RESUMO: Este artigo apresenta uma comparação da intenção empreendedora entre estudantes noruegueses, indonésios e alagoanos utilizando uma metodologia criada por Kristiansen e Indarti (2004). A metodologia propõe a identificação de determinantes da intenção empreendedora e tem como principal objetivo a comparação do impacto dos resultados em diferentes contextos econômicos e sociais. Ela utiliza uma escala formada por 5 constructos (Necessidade de Realização, Lócus de Controle, Auto eficácia, Busca por Informações e Intenção Empreendedora) e 15 variáveis. A pesquisa seguiu uma abordagem quantitativa e descritiva. Foram utilizados os resultados do estudo realizado por Kristiansen e Indarti, com dados coletados na Noruega e Indonésia e de uma nova onde foram aplicados 339 questionários em universitários de quatro instituições de nível superior. Comparando-se os dados coletados por Kristiansen e Indarti com os obtidos em Alagoas verificou-se uma melhor adequação da metodologia aos alagoanos.
\end{abstract}

PALAVRAS-CHAVE: Empreendedorismo, Comportamento Empreendedor, Intenção Empreendedora.

ABSTRACT : This article presents a comparison of entrepreneurial intention among Norwegian, Indonesian and Alagoans students using a methodology created by Kristiansen and Indarti (2004). The methodology proposes the identification of determinants of entrepreneurial intention and its main objective is to compare the impact of the results in different social and economic contexts. It uses a scale consisting of five constructs (Need for Achievement, Locus of Control, Self-efficacy, Search Information and Entrepreneurial Intention) and 15 variables. The study followed a quantitative and descriptive method. We used the results of Kristiansen's and Indarti study, with data collected in Norway and Indonesia, and a new location where 339 questionnaires were applied in four academic institutions of higher education. Comparing the data collected by Kristiansen and Indarti with those obtained in Alagoas the study verified that the methodology was more appropriate in the Alagoan context.

KEYWORDS: Entrepreneurship, Entrepreneurial Behavior, Entrepreneurial Intention.

\footnotetext{
${ }^{1}$ Artigo Recebido em 06.10.2010. Revisado por pares em 03.11.2010. Recomendado em 10.03.2011 por Leomar dos Santos Editor. Publicado em 25.07.2011.

Organização Responsável pelo periódico: Universidade regional de Blumenau - FURB - www.furb.br/rn
}

\footnotetext{
${ }^{2}$ Universidade Federal do Paraná - UFPR - thiagocn1@hotmail.com

${ }^{3}$ Universidade Federal de Alagoas - UFAL - anderson.admead@gmail.com

${ }^{4}$ Universidade Federal de Alagoas - UFAL - paulodacruzfreire@gmail.com

${ }^{5}$ Universidade Federal do Rio Grande do Norte - UFRN - manoel.veras@uol.com.br

${ }^{6}$ Universidade Federal do Rio Grande do Norte - UFRN - antonio.gil@gmail.com
} 


\section{INTRODUÇÃO}

A atividade empreendedora e a própria figura do empreendedor, cada vez mais, ganham destaque no turbulento ambiente econômico em que se depara a sociedade, como alternativa para geração de emprego e renda.

Entre as formas de atuação de um empreendedor, destaca-se, no Brasil, a criação de micro e pequenas empresas que segundo o IBGE (2003) contribuem para o desenvolvimento econômico do país amortecendo o desemprego de uma grande parcela da população com níveis de qualificação menos elevados. Em outras palavras, são responsáveis por absorver uma parcela da mão-de-obra considerada desqualificada por grandes empresas.

Seguindo essa linha de raciocínio, Mazzarol et al (1999) afirmam que os empreendedores têm criado milhares de novos negócios a cada ano enquanto grandes empresas têm instituído políticas de downsizing. Para os autores, a criação de empregos e o desenvolvimento econômico têm se tornado responsabilidades dos empreendedores.

Esta mudança de postura por parte das grandes empresas tem início, segundo Dias (2001), a partir do século XX. Momento no qual as sociedades ocidentais começaram a passar por mudanças advindas do capitalismo, da tecnologia e de outras variáveis que ocasionam uma série de implicações no universo social. O fator tecnologia favoreceu a automação do trabalho, gerando desemprego e mortalidade de empresas, que não conseguiram acompanhar o desenvolvimento tecnológico ocorrido durante o século XX. Este, entre outros fatores, fez com que os indivíduos buscassem alternativas de sobrevivência, as quais, geralmente, culminam em ações empreendedoras.

Apesar de ter sua importância reconhecida, no que diz respeito ao desenvolvimento de novos negócios, a atividade empreendedora no Brasil, está, muitas vezes, direcionada a um meio de sobrevivência, ou seja, a uma alternativa de geração de emprego e renda também conhecida como empreendedorismo por necessidade. (GEM, 2006; ALMEIDA; BENEVIDES, 2005; CÂMARA et al., 2005; BARRETO et al, 2006; NASCIMENTO JR.; DANTAS; SANTOS, 2005).

Já em 1987, Peter Drucker justificava a crescente importância dos estudos direcionados à figura do empreendedor, tida para o autor como uma peça chave para a sociedade e a economia, por meio das inovações desenvolvidas por estas pessoas.

Dolabela (2003, p. 21) acrescenta outros elementos à discussão ao afirmar que "a necessidade de aumentar a capacidade empreendedora não é apenas resposta à retração atual do nível de emprego - verdadeira -, mas decorrência direta de novos padrões de relações sociais e políticas que incluem o mercado, mas não se limitam a ele”.

É neste sentido que o empreendedorismo também pode ser visto como indutor de desenvolvimento regional, de forma a reduzir desigualdades em um ambiente de incertezas e ambiguidades, promovendo, por meio da atividade empreendedora, maior dinamismo econômico e social (JULIEN, 2007).

Diante disto, a mensuração do potencial empreendedor é importante tanto para aqueles que acreditam no ensino do empreendedorismo quanto para os que postulam que as características empreendedoras são virtudes intrínsecas à personalidade do indivíduo. Para os primeiros, os resultados deste tipo de pesquisa serviriam na avaliação do grau/nível 
empreendedor em que os indivíduos se encontram para, a partir daí, complementar os ensinamentos necessários. Para o segundo grupo, a avaliação torna-se imprescindível como indicador na escolha de projetos pelos Venture Capitalists. A grande questão que se coloca é o da confiabilidade de tais instrumentos de mensuração.

Neste ponto, urge verificar os instrumentos que são desenvolvidos por estudiosos da vertente comportamental em diversas localidades, submetendo-os a comparações que podem influenciar positiva ou negativamente sua aplicabilidade em diferentes locais, em decorrência de fatores sociais, culturais e econômicos que agem sobre os indivíduos.

Tendo em vista a importância do empreendedor para o desenvolvimento econômico e a necessidade de estabelecer instrumentos que ajudem na compreensão da intenção de empreender, a pesquisa teve por objetivo avaliar, em Alagoas, a metodologia desenvolvida por Kristiansen e Indarti (2004) em estudos na Noruega e Indonésia, através de uma comparação de seus resultados com estudantes universitários alagoanos.

\subsection{EMPREENDEDORISMO}

As discussões acerca do tema empreendedorismo, como se verificam atualmente, podem ser consideradas um fenômeno recente, e são decorrentes da crença de que os empreendedores são atores fundamentais para o desenvolvimento econômico e para a redução de disparidades sociais num cenário de incertezas cada vez mais complexas, onde a capacidade de inovar aparece como fator essencial para qualquer atividade relacionada ao ambiente corporativo.

A literatura que apoia esta ideia tem como principal base os escritos de autores como Schumpeter (1934) e Leibenstein (1968) que procuram explicar qual o papel do empreendedor no desenvolvimento econômico. Adotando uma postura diferente autores como Baumol (1968) abordam a temática de forma distinta, tentando contextualizar o empreendedorismo na teoria econômica e diferenciar a figura do empreendedor de um gestor organizacional comum.

Com o crescimento das discussões sobre o tema, principalmente após os escritos de Schumpeter (1934), o empreendedorismo passou a ser visto não apenas como um fenômeno dentro da esfera econômica e ganhou novas perspectivas de estudo como a psicológica apoiada nos estudos de McClelland (1961). Constituindo, juntamente com Schumpeter (1934), um dos principais autores no que concerne ao campo do empreendedorismo.

Apesar dessa temática ter sua ascensão apoiada nos escritos elaborados por Shumpeter (1934), principalmente com base no conceito de destruição criativa (em que esta ocorreria se as estruturas de mercado fossem destruídas pela entrada competitiva de novas combinações inovadoras que impulsionassem a evolução dinâmica da economia), alguns autores o precederam no estudo do empreendedor, como Cantillon (1755) e Jean-Baptiste Say (1832).

O responsável por conceder ao empreendedor sua primeira definição é Cantillon (1755) que, já no século XVIII, o relacionava a pessoas que compravam matéria-prima e a vendia a terceiros, identificavam oportunidades de negócio e além de lidar com inovação, investiam seus próprios recursos e corriam riscos. 
THIAGO CAVALCANTE NASCIMENTO

PAULO DA CRUZ FREIRE DOS SANTOS

ANTONIO GIL DA COSTA JUNIOR
ANDERSON DE BARROS DANTAS

MANOEL VERAS

Cantillon (1755) foi pioneiro na defesa do empreendedor no cenário econômico, segmentando suas teorias em três classes: os empreendedores, os proprietários de terra e os trabalhadores, considerando os empreendedores os responsáveis pelas mudanças e pelo desenvolvimento do sistema produtivo.

Mesmo com o pioneirismo de Cantillon (1755) é Jean-Baptiste Say quem pode ser considerado o “pai” do empreendedorismo e juntamente com Cantillon considerou o empreendedor a pessoa que aproveitava oportunidades com o objetivo de obter lucro e assumir riscos, além de associar a figura do empreendedor à inovação (GUIMARÃES, 2004, grifo nosso).

Jean-Baptiste Say também é analisado sob diferentes óticas, como a apontada por Drucker (1987) que argumenta que Say considerava o empreendedor como aquele que transferia recursos de um setor de produtividade baixa para um setor de produtividade mais elevada e de maior rendimento.

É interessante acrescentar que apesar do avanço que envolve a temática, não é possível dizer ao certo quando surgiu a figura do empreendedor, apesar de alguns autores o tentarem como Dutra e Previdelli (2003) ao afirmar que manifestações empreendedoras remontam às práticas mercantis, como as dos fenícios e árabes, as quais proporcionaram o crescimento e desenvolvimento econômico da maioria dos continentes civilizados. Outros autores, como Dornelas (2001) sugere que o primeiro exemplo de empreendedor poderia ser relacionado a Marco Polo, quando este assinou um contrato para vender mercadorias de outro homem, assumindo papel ativo, correndo todos os riscos físicos e emocionais, na tentativa de estabelecer uma rota comercial para o Oriente.

Apesar das inúmeras divergências sobre quando o empreendedor surgiu, quais as características que predominam em seu ambiente psicológico e qual seu papel no cenário empresarial contemporâneo, inúmeras outras questões surgem constantemente, principalmente em relação à importância da figura no empreendedor no desenvolvimento econômico.

É neste sentido que Julien (2007) ressalta a importância do empreendedorismo para o desenvolvimento regional e local. Para o autor, a questão do desenvolvimento endógeno perpassa tanto a criação de negócios como a expansão dos existentes, o que, segundo o autor, é inerentemente, uma atividade empreendedora.

Como consequência da crença de que os empreendedores agem como indutores de desenvolvimento econômico e social, instituições foram criadas para dar suporte à atividade empreendedora. O principal exemplo disto é o Global Entrepreneurship Monitor (GEM), formado como um consórcio de diversas universidades de diferentes localidades que coletam dados anualmente sobre o empreendedorismo no mundo. Segundo esta instituição os países que proporcionam o desenvolvimento da atividade empreendedora apresentam níveis mais elevados de competitividade devido à inovação, aplicação de tecnologia e criação de novos mercados (GEM, 2006).

No Brasil, alguns exemplos de instituições voltadas para apoiar a atividade empreendedora são o Serviço de Apoio às Micro e Pequenas Empresas (Sebrae) que tem como base de sua filosofia o apoio à abertura e expansão de pequenos negócios e a 


\section{A METODOLOGIA DE KRISTIANSEN E INDARTI PARA IDENTIFICAR INTENÇÃO EMPREENDEDORA EM ESTUDANTES DE ENSINO SUPERIOR: COMPARANDO RESULTADOS OBTIDOS NA NORUEGA, INDONÉSIA E ALAGOAS.}

Associação Nacional de Entidades Promotoras de Empreendimentos Inovadores (Anprotec) que tem como objetivo dar apoio às incubadoras de empresas.

Há de se salientar que a crença de que a atividade empreendedora está diretamente relacionada ao desenvolvimento econômico continua sendo uma hipótese que tem seus pilares na intuição de pesquisadores, no senso comum e na pura observação da atividade econômica (UNCTAD, 2004). Desta forma, apesar de o tema estar diretamente relacionada à inovação, flexibilidade, conhecimento e competitividade (JULIEN, 2007; SCHUMPETER, 1934. DRUCKER, 1987), seus impactos sobre a economia continuam, de certa forma, incompreendidos fomentando o desenvolvimento de inúmeras teorias e modelos para análise deste fenômeno (UNCTAD, 2004).

\subsection{COMPORTAMENTO EMPREENDEDOR}

Os estudos direcionados à análise das atitudes empreendedoras são, na maioria das vezes, desenvolvidos sob a ótica comportamentalista, cujo principal expoente pode ser considerado David C. McClelland (1961).

$\mathrm{Na}$ abordagem comportamental o empreendedor é visto como aquela pessoa capaz de criar uma visão, persuadir terceiros, atrair sócios, envolver colaboradores, convencer investidores, desenvolver pessoas com energia e perseverança. Além de tudo possui a paixão para construir algo do nada, ao acreditar que pode colocar a sorte a seu favor ao assumir esta mesma sorte como decorrência do trabalho árduo, entendendo que ela faz parte do trabalho cotidiano (DOLABELA, 1999a).

Ao avançar em tal perspectiva, Filion e Dolabela (2000) afirmam que o empreendedor se configura como um sujeito atento aos acontecimentos com o intuito de traçar diretrizes, corrigir rumos e, desta forma, atingir os espaços por ele almejados. Em suma, o empreendedor se mantém permanentemente alerta aos mínimos sinais de mudanças face à consciência do grande impacto que elas podem vir a assumir tanto em seus negócios quanto em suas vidas.

Os autores assumem que o comportamento empreendedor faz parte de um processo que comporta várias dimensões da vida e admite diferentes escolhas. Filion e Dolabela (2000, p. 25) ainda definem empreendedor como "uma pessoa que empenha toda a sua energia na inovação e no crescimento, manifestando-se de duas maneiras: criando uma empresa ou desenvolvendo alguma coisa completamente nova em uma empresa preexistente”. Dornelas (2001, p. 19) complementa esta definição, afirmando que "os empreendedores são pessoas diferenciadas, que possuem motivação singular, apaixonadas pelo que fazem, não se contentam em ser mais um na multidão, querem ser reconhecidas e admiradas, referenciadas e imitadas, querem deixar um legado.

Tomando como base as inúmeras características levantadas por diversos pesquisadores acerca dos traços comportamentais presentes nos empreendedores, é possível dizer que a literatura ainda se encontra distante de um consenso apesar de inúmeros trabalhos serem desenvolvidos com este enfoque.

O estudo de McClelland (1961), o precursor desse tipo de análise, foi considerado um dos mais relevantes, no que diz respeito à determinação das características empreendedoras. Em seu trabalho o pesquisador considerou que as principais variáveis relacionadas ao 
comportamento empreendedor dizem respeito à busca por oportunidades, busca por informação, comprometimento, persistência, capacidade de planejamento, autoconfiança, assumir riscos calculados e poder de persuasão.

Em estudo mais recente, desenvolvido por Kristiansen e Indarti (2004) com estudantes universitários indonésios e noruegueses, foram consideradas como características empreendedoras a intenção de empreender, a necessidade de realização, a busca por informação, o lócus de controle e a auto eficácia.

Em relação ao contexto brasileiro, Paiva Jr., Leão e Mello (2003) realizaram um estudo onde as competências associadas ao comportamento de dirigentes de perfil empreendedor encontradas foram: competências de oportunidade, relacionamento, conceituais, administrativas, estratégicas, comprometimento e competências de equilíbrio trabalho/vida pessoal.

Como pode ser visto, ainda não foi possível estabelecer uma convergência científica que determine o perfil ideal de um empreendedor. Segundo Pereira e Costa (2006) isto ocorre devido a inúmeros fatores que podem estar relacionados ao nível de escolaridade, a religião, a cultura familiar, a experiência profissional, entre outros. Neste sentido, se aceita que o desenvolvimento das características individuais é influenciado pelo ambiente nos quais as pessoas estão inseridas, variando de acordo com as especificidades de cada país ou região.

Mesmo sem conotações determinísticas, acredita-se que o estudo destas características contribui para a identificação e a compreensão de comportamentos que podem levar o empreendedor ao sucesso (DOLABELA, 1999b). O desenvolvimento de métodos de avaliação que busquem uma maior clareza e objetividade ao caracterizar o perfil empreendedor pode ser útil para os diversos atores envolvidos nos processos de inovação e desenvolvimento, crescentemente requeridos pela sociedade.

\subsection{O MODELO DE KRISTIANSEN E INDARTI}

A metodologia desenvolvida pelo norueguês Stein Kristiansen (professor da Agda University College) e pela indonésia Nurul Indart (professora da Gadjah Mada University), em 2004, propõe verificar fatores determinantes da intenção empreendedora, através do estabelecimento de 5 constructos teórico-empíricos (Necessidade de Realização, Lócus de Controle, Eficácia Própria, Busca por Informação e Intenção Empresarial), subdivididos em 15 variáveis, que assumem o formato de um questionário estruturado.

O modelo de pesquisa elaborado por Kristiansen e Indarti (2004) toma por base uma série de fatores como elementos formadores da intenção empresarial e os diferencia em três grupos analíticos: 1) fatores demográficos e contexto individual; 2) personalidades e atitudes; e 3) elementos contextuais.

Em relação aos fatores demográficos e o contexto individual os autores argumentam que inúmeros estudos dão suporte ao fato de que características demográficas como o gênero, a idade e o contexto individual como experiência profissional e nível educacional exercem impacto sobre o comportamento empreendedor (KRISTIANSEN; INDARTI, 2004).

O grupo referente à personalidade e atitudes foi formado por constructos referentes à necessidade de realização, lócus de controle e eficácia própria. As variáveis relacionadas à 


\section{A METODOLOGIA DE KRISTIANSEN E INDARTI PARA IDENTIFICAR INTENÇÃO EMPREENDEDORA EM ESTUDANTES DE ENSINO SUPERIOR: COMPARANDO RESULTADOS OBTIDOS NA NORUEGA, INDONÉSIA E ALAGOAS.}

necessidade de realização foram construídas tomando como base os estudos de McClelland no qual a presença deste traço comportamental influência indivíduos a uma maior intenção empreendedora. O lócus de controle foi analisado como uma característica que indica o nível individual de controle dos sentimentos dos indivíduos e a eficácia própria como a crença de uma pessoa em executar determinada tarefa (KRISTIANSEN; INDARTI, 2004).

No que concerne aos elementos contextuais, os autores argumentam em sua base teórica que fatores ambientais como características culturais, rede de relacionamentos, condições econômicas e políticas, bem como a infraestrutura institucional também afetam a intenção empreendedora. Nesta dimensão os autores abordam três características fundamentais: acesso à capital; acesso à informação; e rede de contatos sociais. O acesso ao capital é tratado como um dos típicos obstáculos para a abertura de pequenos negócios. Já o acesso à informação foi analisado como a freqüência com que um indivíduo faz contato com diferentes fontes de informação. A última característica (rede de contatos sociais) foi analisada como uma série de laços formais e informais entre um ator central (empreendedor) e demais atores para que um negócio consiga ser iniciado (KRISTIANSEN; INDARTI, 2004).

No que concerne à variável dependente do estudo, ou seja, a intenção empresarial ou intenção empreendedora, Grundsten (2004) a define como uma medida de comportamento de um indivíduo que pode resultar em uma atividade empresarial. É seguindo esta linha de raciocínio que se encontra a abordagem utilizada por Kristiansen e Indarti (2004), considerando esta dimensão como a predisposição dos indivíduos para iniciar um negócio.

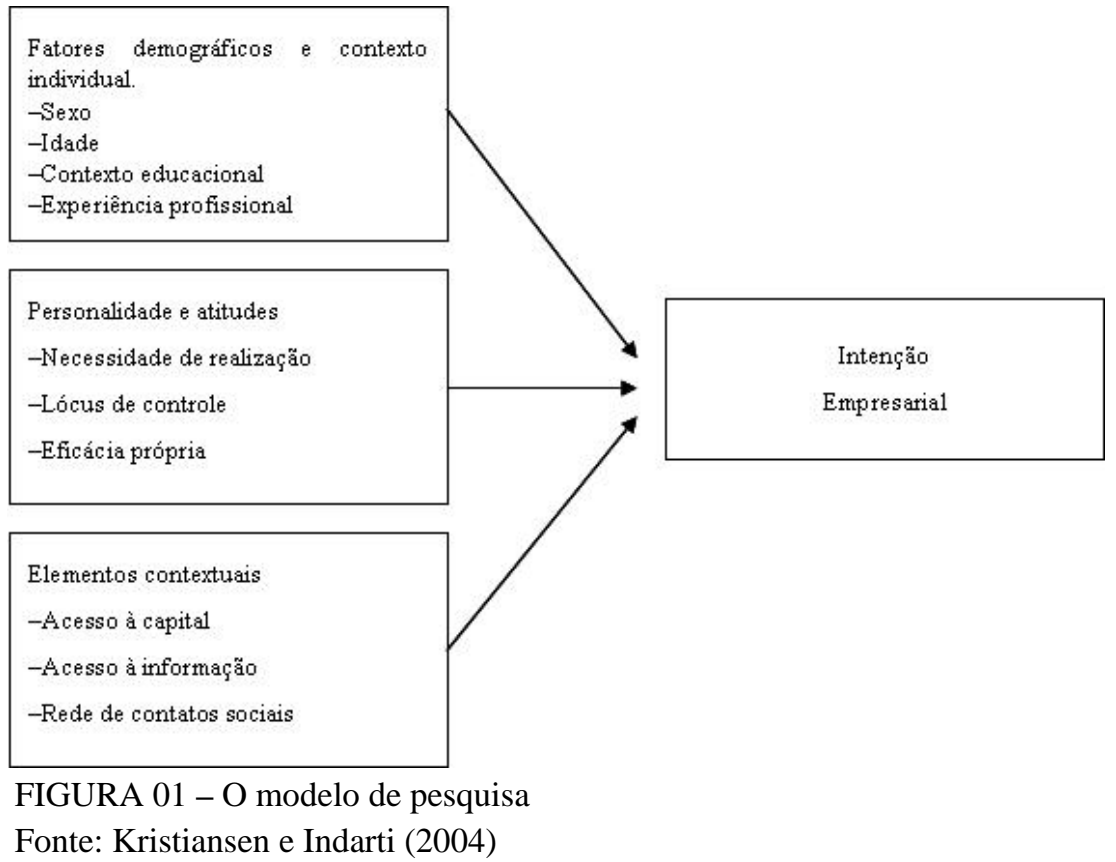

Com base em seu referencial teórico Kristiansen e Indarti (2004) elaboraram cinco hipóteses para análise empírica (também utilizadas neste estudo para dar suporte à proposta comparativa da pesquisa), listadas a seguir: 
$\mathrm{H}_{1}$ - Fatores demográficos e o contexto individual, como a idade, sexo, educação e experiência profissional têm influência na intenção empresarial.

$\mathrm{H}_{2}$ - Necessidade de realização alta tem um impacto positivo na intenção empresarial.

$\mathrm{H}_{3}$ - Altas pontuações referentes a lócus de controle são correlacionadas positivamente com a intenção empresarial.

$\mathrm{H}_{4}$ - Altas pontuações referentes à eficácia própria são correlacionadas positivamente com intenção empresarial.

$\mathrm{H}_{5}$ - Busca por informação é um prognóstico significativamente positivo da intenção empresarial.

Cabe aqui destacar que a amostra utilizada por Kristiansen e Indarti (2004) foi constituída por 130 estudantes universitários da Gadja Mada University (UGM) em Yogyakarta, na Indonésia, e 121 estudantes da Agder University College (AUC) em Kristiansand, na Noruega. Os questionários aplicados na língua de cada um dos países constituintes da amostra e a pesquisa de campo ocorreu entre abril de 2002 e julho de 2002 por meio do critério de conveniência, tornando a amostra não probabilística.

\section{PROCEDIMENTOS METODOLÓGICOS}

Para a consecução do objetivo do estudo de avaliar, em Alagoas, o instrumento componente da metodologia de avaliação de intenção empreendedora, desenvolvida por Kristiansen e Indarti (2004), através de uma pesquisa comparativa, optou-se por uma metodologia de natureza quantitativa, visto que se trabalhou essencialmente com escalas numéricas, e caráter descritivo, onde variáveis foram observadas, registradas e correlacionadas, no decorrer do estudo (CERVO; BERVIAN, 2002).

A amostra inicial foi composta por 420 estudantes de instituições de ensino superior. No entanto, a amostra final foi constituída por 339 respondentes. A exclusão de 81 elementos se deu em decorrência de falta de resposta em alguns quesitos que impossibilitariam a comparação com os resultados obtidos por Kristiansen e Indarti (2004) em seu estudo.

O processo de amostragem foi não probabilístico e se deu de acordo com o critério de acessibilidade. E, apesar de a margem de erro e o nível de confiabilidade serem desconsiderados neste tipo de procedimento, a quantidade de questionários aplicados representaria um erro próximo a 5,3\%, considerando o nível de confiança em 95\% com base nos procedimentos de amostragem infinita. Participaram da pesquisa estudantes de graduação de 4 instituições de ensino superior, sendo uma delas federal e as demais particulares.

Salienta-se que a amostra final do estudo foi significativamente superior à obtida por Kristiansen e Indarti (2004) em seu trabalho. Tal ocorrência não prejudica o processo de análise, pois dá maior consistência na explicação dos resultados encontrados nesta pesquisa, reduzindo seu erro amostral e a amplitude de variância dos dados.

Sobre as características que envolvem os diferentes públicos em análise, destaca-se que o estado de Alagoas apresenta características singulares em relação aos países em que Kristiansen e Indarti (2004) realizaram seu estudo, principalmente em relação a indicadores econômicos e sociais. Em comparação com a Noruega, o estado de Alagoas se mostra 


\section{A METODOLOGIA DE KRISTIANSEN E INDARTI PARA IDENTIFICAR INTENÇÃO EMPREENDEDORA EM ESTUDANTES DE ENSINO SUPERIOR: COMPARANDO RESULTADOS OBTIDOS NA NORUEGA, INDONÉSIA E ALAGOAS.}

significativamente atrasado em todos os aspectos direcionados aos indicadores dos grupos citados. Tal fenômeno não ocorre quando são analisados dados de Alagoas com os da Indonésia, com exceção para as grandes cidades deste último, que apresentam taxas de crescimento significativamente mais elevadas do que as apresentadas no estado de Alagoas.

Todos os respondentes foram orientados para assinalar apenas um item em cada variável, correspondente ao grau de sua relação com a afirmação feita pelo instrumento, que possuía uma escala do tipo Likert de 7 pontos, onde o primeiro ponto representava total discordância e o sétimo ponto concordância total. A utilização de tal escala se deu por adequação com o modelo teórico utilizado como base da pesquisa.

Duas das variáveis do instrumento de coleta de dados (LC2 - Se eu não tiver sucesso em uma atividade/tarefa, eu tendo a desistir e IE2 - Eu quero seguir uma carreira como empregado(a) em uma empresa/organização) visualizadas no quadro a seguir, receberam tratamento de tabulação inversa para não enviesar a análise estatística. Tal procedimento se deu com base no fato de que estas variáveis caminham em sentido oposto ao que se espera de um empreendedor no arcabouço teórico deste estudo.

\begin{tabular}{|c|c|c|}
\hline \multirow{4}{*}{$\begin{array}{c}\text { Necessidade } \\
\text { de } \\
\text { Realização }\end{array}$} & NR1 & $\begin{array}{l}\text { Em relação ao meu trabalho e / ou aos meus estudos eu me saio muito bem nas tarefas } \\
\text { consideradas muito difíceis. }\end{array}$ \\
\hline & NR2 & Tento intensamente melhorar em relação ao que já realizei no passado. \\
\hline & NR3 & Busco responsabilidades adicionais nos trabalhos que me dão para fazer. \\
\hline & NR4 & Tento atuar mais do que os (as) meus (minhas) colegas. \\
\hline \multirow{3}{*}{$\begin{array}{l}\text { Lócus de } \\
\text { Controle }\end{array}$} & LC1 & Acredito que empenho e trabalho intenso geralmente levam ao sucesso. \\
\hline & LC2 & Se eu não tiver sucesso em uma atividade / tarefa, eu tendo a desistir. \\
\hline & LC3 & Eu, com certeza, não acredito em sorte. \\
\hline \multirow{2}{*}{$\begin{array}{l}\text { Eficácia } \\
\text { Própria }\end{array}$} & EP1 & $\begin{array}{l}\text { Eu tenho as habilidades de liderança que são necessárias para me tornar um (a) } \\
\text { empreendedor (a). }\end{array}$ \\
\hline & EP2 & Eu tenho maturidade mental (psicológica) para começar a ser um (a) empreendedor (a). \\
\hline \multirow{3}{*}{$\begin{array}{l}\text { Busca por } \\
\text { Informação }\end{array}$} & BI1 & Eu tenho acesso a capital parara começar a ser um (a) empreendedor (a). \\
\hline & $\mathrm{BI} 2$ & $\begin{array}{l}\text { Eu tenho uma boa rede de contatos sociais que pode ser utilizada quando eu decidir me } \\
\text { tornar um (a) empreendedor (a). }\end{array}$ \\
\hline & BI3 & Eu tenho acesso a informações de apoio para começar a ser um (a) empreendedor. \\
\hline \multirow{3}{*}{$\begin{array}{c}\text { Intenção } \\
\text { Empresarial }\end{array}$} & IE1 & Eu quero seguir uma carreira como empreendedor (a). \\
\hline & IE2 & Eu quero seguir uma carreira como empregado (a) em uma empresa / organização. \\
\hline & IE3 & $\begin{array}{l}\text { Eu prefiro ser um (a) empreendedor (a) do que um (a) empregado (a) em uma empresa / } \\
\text { organização. }\end{array}$ \\
\hline
\end{tabular}

QUADRO 01 - Constructos e Variáveis do Instrumento de Coleta de Dados

Fonte: Adaptado de KRISTIANSEN; INDARTI (2004)

Os dados coletados foram devidamente organizados e tabulados através do software SPSS $^{\circledR}$ - Statistic Package for Social Sciences, por se apresentar como uma das principais ferramentas de análise de dados na área das ciências sociais aplicadas.

O processo de análise de dados se deu através dos procedimentos estatísticos descritivos como média e desvio padrão e inferenciais como comparação de médias ( $t$-test), correlação de Pearson e regressão múltipla seguindo exatamente os mesmo passos do estudo de Kristiansen e Indarti (2004).

O teste $t$, também conhecido como $t$ de Student é utilizado para verificar diferenças entre dois grupos (pareados ou independentes), mais especificamente, em diferenças de 
THIAGO CAVALCANTE NASCIMENTO

PAULO DA CRUZ FREIRE DOS SANTOS

ANTONIO GIL DA COSTA JUNIOR
ANDERSON DE BARROS DANTAS

MANOEL VERAS

médias (MALHOTRA, 2006; DANCEY, 2006). Este teste, apesar de ser considerado pela literatura como não paramétrico, apresenta distribuição próxima da normal (MALHOTRA, 2006).

O teste de correlação de Pearson é utilizado para verificar se existe um relacionamento entre duas variáveis discretas ou contínuas que siga a distribuição normal (DANCEY, 2006). De acordo com Cunha e Coelho (2007: p.140) a correlação "mede a força do relacionamento ou grau de associação entre duas variáveis. Duas variáveis são altamente correlacionadas se as mudanças ocorridas em uma delas estiverem fortemente associadas com as mudanças ocorridas na outra”.

A análise de regressão é uma técnica de análise multivariada que por meio de uma função matemática determina uma relação causal entre variáveis independentes e uma variável dependente (HAIR et al, 2005; CUNHA; COELHO, 2007; MALHOTRA, 2006). De acordo com Hair et al (2005: p.131) “análise de regressão é de longe a técnica de dependência mais amplamente usada e versátil, aplicável em cada faceta da tomada de decisões em negócios.” O autor ainda complementa dizendo que esta técnica consiste em "uma ferramenta analítica poderosa planejada para explorar todos os tipos de relações de dependência.”

\section{APRESENTAÇÃO E DISCUSSÃO DOS RESULTADOS}

Inicialmente, foi traçado o perfil individual dos entrevistados, seguido de uma avaliação das características empreendedoras e, após isso, foram realizados testes de hipóteses correspondentes aos mesmos procedimentos adotados por Kristiansen e Indarti (2004).

\begin{tabular}{|c|c|c|c|c|c|c|c|}
\hline & \multirow[t]{2}{*}{ Itens } & \multicolumn{2}{|c|}{$\begin{array}{l}\text { Noruegueses } \\
\quad(n=121)\end{array}$} & \multicolumn{2}{|c|}{$\begin{array}{c}\text { Indonésios } \\
(n=130)\end{array}$} & \multicolumn{2}{|c|}{$\begin{array}{c}\text { Alagoanos } \\
(n=339)\end{array}$} \\
\hline & & $\mathbf{n}$ & $\%$ & $\mathbf{n}$ & $\%$ & $\mathbf{n}$ & $\%$ \\
\hline \multirow{2}{*}{ Gênero } & Feminino & 45 & 37,2 & 64 & 49,2 & 178 & 52,5 \\
\hline & Masculino & 76 & 62,8 & 66 & 50,8 & 161 & 47,5 \\
\hline \multirow{2}{*}{ Idade } & $<25$ & 61 & 50,4 & 110 & 84,6 & 256 & 75,5 \\
\hline & $>=25$ & 60 & 49,6 & 20 & 15,4 & 83 & 24,5 \\
\hline \multirow{2}{*}{$\begin{array}{c}\text { Contexto } \\
\text { Educacional }\end{array}$} & Disciplinas de Negócios & 83 & 68,6 & 72 & 55,4 & 243 & 71,7 \\
\hline & Outras Disciplinas & 38 & 31,4 & 58 & 44,6 & 96 & 28,3 \\
\hline \multirow{4}{*}{$\begin{array}{l}\text { Experiência } \\
\text { Profissional }\end{array}$} & Sem Experiência & 24 & 19,8 & 73 & 56,2 & 198 & 58,4 \\
\hline & Setor Público & 26 & 21,5 & 8 & 6,2 & 46 & 13,6 \\
\hline & Setor Privado & 51 & 42,1 & 47 & 36,2 & 92 & 27,1 \\
\hline & Ambos os Setores & 20 & 20,0 & 2 & 1,5 & 3 & 0,9 \\
\hline
\end{tabular}

QUADRO 02 - Contexto Individual dos Respondentes

Fonte: KRISTIANSEN; INDARTI (2004); Dados da pesquisa

Em relação ao contexto individual dos respondentes, é possível verificar que apenas em Alagoas o público feminino foi maior que o masculino, no entanto, tal diferença é muito pequena em relação aos alunos entrevistados por Kristiansen e Indarti (2004) na Indonésia. Sobre a idade, foi possível verificar que o público respondente em Alagoas se assemelha muito à realidade encontrada na Indonésia, com mais de $75 \%$ dos entrevistados com idade inferior a 25 anos, diferentemente da realidade encontrada na Noruega, onde praticamente não 


\section{A METODOLOGIA DE KRISTIANSEN E INDARTI PARA IDENTIFICAR INTENÇÃO EMPREENDEDORA EM ESTUDANTES DE ENSINO SUPERIOR: COMPARANDO RESULTADOS OBTIDOS NA NORUEGA, INDONÉSIA E ALAGOAS.}

existem diferenças entre estudantes com idade inferior e superior a 25 anos. Estes resultados podem levar a questionamentos sobre as razões pelas quais estudantes de países em via de desenvolvimento apresentam idades proporcionalmente inferiores em relação aos estudantes de graduação de países desenvolvidos como a Noruega.

No que diz respeito ao contexto educacional, encontrou-se maior semelhança entre o público entrevistado em Alagoas com o da Noruega, onde, em ambos os casos, cerca de $70 \%$ dos alunos estão em cursos relacionados ao gerenciamento de negócios. Na Indonésia os entrevistados também são, em sua maioria, estudantes de cursos de negócios, no entanto, a representatividade foi menor. Esta diferença na proporção entre a Indonésia e a Noruega pode ser originada do procedimento de seleção dos indivíduos constituintes da amostra de Kristiansen e Indarti (2004).

Em relação à experiência profissional, foram obtidos resultados dispares em relação à Noruega em comparação com a Indonésia e Alagoas. Segundo os dados de Kristiansen e Indarti (2004) são poucos os estudantes noruegueses que não possuem experiência profissional, o que difere dos resultados encontrados na Indonésia e neste estudo sobre os estudantes alagoanos.

De forma geral, verifica-se que Alagoas não apresentou características de homogeneidade com nenhum dos dois países presentes no estudo de Kristiansen e Indarti (2004). Destaca-se, ainda, que Alagoas apresenta características sócio-demográficas significativamente diferentes da Noruega e Indonésia (que já são distintas entre si), como densidade populacional, taxas de crescimento, índice de desenvolvimento humano, renda per capita, entre outros.

\begin{tabular}{|c|c|c|c|c|c|c|c|}
\hline \multirow[t]{2}{*}{ Constructos } & \multirow[t]{2}{*}{ Variáveis } & \multicolumn{2}{|c|}{$\begin{array}{l}\text { Noruegueses } \\
(\mathbf{n}=121)\end{array}$} & \multicolumn{2}{|c|}{$\begin{array}{l}\text { Indonésios } \\
(\mathbf{n}=130)\end{array}$} & \multicolumn{2}{|c|}{$\begin{array}{c}\text { Alagoanos } \\
(\mathrm{n}=339)\end{array}$} \\
\hline & & Média & Desvio & Média & Desvio & Média & Desvio \\
\hline \multirow{4}{*}{$\begin{array}{l}\text { Necessidade de } \\
\text { Realização } \\
\text { (NACH) }\end{array}$} & $\begin{array}{l}\text { Em relação ao meu trabalho e / } \\
\text { ou aos meus estudos eu me saio } \\
\text { muito bem nas tarefas } \\
\text { consideradas muito difíceis. }\end{array}$ & 4,70 & 1,05 & 5,78 & 1,06 & 4,78 & 1,17 \\
\hline & $\begin{array}{l}\text { Tento intensamente melhorar em } \\
\text { relação ao que já realizei no } \\
\text { passado. }\end{array}$ & 4,95 & 1,12 & 6,20 & 0,98 & 6,01 & 1,08 \\
\hline & \begin{tabular}{ll|} 
Busco responsabilidades \\
adicionais nos \\
dão para fazer.
\end{tabular} & 4,94 & 1,17 & 4,69 & 1,42 & 4,88 & 1,52 \\
\hline & $\begin{array}{l}\text { Tento atuar mais do que os (as) } \\
\text { meus (minhas) colegas. }\end{array}$ & 4,56 & 1,37 & 5,92 & 1,03 & 4,59 & 1,62 \\
\hline \multirow{3}{*}{$\begin{array}{l}\text { Lócus de } \\
\text { Controle } \\
\text { (LOC) }\end{array}$} & $\begin{array}{l}\text { Acredito que empenho e trabalho } \\
\text { intenso geralmente levam ao } \\
\text { sucesso. }\end{array}$ & 5,55 & 1,19 & 6,43 & 0,95 & 6,19 & 1,19 \\
\hline & $\begin{array}{l}\text { Se eu não tiver sucesso em uma } \\
\text { atividade / tarefa, eu tendo a } \\
\text { desistir. }\end{array}$ & 2,71 & 1,46 & 2,86 & 1,72 & 2,61 & 1,64 \\
\hline & $\begin{array}{l}\text { Eu, com certeza, não acredito em } \\
\text { sorte. }\end{array}$ & 3,52 & 1,59 & 4,78 & 1,30 & 3,52 & 1,94 \\
\hline
\end{tabular}




\begin{tabular}{|c|c|c|c|c|c|c|c|}
\hline \multirow{2}{*}{$\begin{array}{l}\text { Eficácia Própria } \\
\text { (SELFEFF) }\end{array}$} & $\begin{array}{l}\text { Eu tenho as habilidades de } \\
\text { liderança que são necessárias } \\
\text { para me tornar um (a) } \\
\text { empreendedor (a). }\end{array}$ & 4,32 & 1,24 & 4,82 & 1,39 & 4,52 & 1,60 \\
\hline & $\begin{array}{l}\text { Eu tenho maturidade mental } \\
\text { (psicológica) para começar a ser } \\
\text { um (a) empreendedor (a). }\end{array}$ & 4,07 & 1,38 & 4,52 & 1,31 & 4,81 & 1,59 \\
\hline \multirow{3}{*}{$\begin{array}{c}\text { Rede de } \\
\text { Relacionamentos } \\
\text { (INSREAD) }\end{array}$} & \begin{tabular}{|lll} 
Eu tenho acesso a capital parara \\
começar a ser um \\
empreendedor (a).
\end{tabular} & 2,57 & 1,61 & 3,66 & 1,50 & 2,65 & 1,72 \\
\hline & $\begin{array}{l}\text { Eu tenho uma boa rede de } \\
\text { contatos sociais que pode ser } \\
\text { utilizada quando eu decidir me } \\
\text { tornar um (a) empreendedor (a). }\end{array}$ & 3,91 & 1,32 & 4,46 & 1,54 & 3,68 & 1,82 \\
\hline & $\begin{array}{l}\text { Eu tenho acesso a informações de } \\
\text { apoio para começar a ser um (a) } \\
\text { empreendedor. }\end{array}$ & 3,46 & 1,48 & 4,59 & 1,43 & 4,46 & 1,70 \\
\hline \multirow{3}{*}{$\begin{array}{l}\text { Intenção } \\
\text { Empresarial } \\
\text { (INTENT) }\end{array}$} & $\begin{array}{l}\text { Eu quero seguir uma carreira } \\
\text { como empreendedor (a). }\end{array}$ & 2,86 & 1,40 & 4,75 & 1,54 & 4,54 & 1,92 \\
\hline & $\begin{array}{l}\text { Eu quero seguir uma carreira } \\
\text { como empregado (a) em uma } \\
\text { empresa / organização }\end{array}$ & 5,04 & 1,40 & 4,40 & 1,73 & 3,77 & 1,85 \\
\hline & $\begin{array}{l}\text { Eu prefiro ser um (a) } \\
\text { empreendedor (a) do que um (a) } \\
\text { empregado (a) em uma empresa / } \\
\text { organização. }\end{array}$ & 3,28 & 1,62 & 5,03 & 1,55 & 5,02 & 1,88 \\
\hline
\end{tabular}

QUADRO 03 - Avaliação das Características Empreendedoras

Fonte: KRISTIANSEN; INDARTI (2004); Dados da pesquisa

Seguindo os pressupostos metodológicos apontados por Kristiansen e Indarti (2004) em seu trabalho, foi realizado o teste de consistência interna utilizando-se o alfa de Cronbach para verificar a confiabilidade da escala. O resultado do teste foi de 0,718 , o que permite dizer que a escala é confiável, ou seja, apresenta padrões mínimos de consitência. (HAIR et al, 2005; MALHOTRA, 2006; RODRIGUES; PAULO, 2007).

De acordo com os dados apresentados no quadro 3, é possível verificar que em 12 dos 15 indicadores presentes no instrumento de coleta de dados os escores dos indonésios são maiores do que os dos noruegueses e dos alagoanos.

Os noruegueses apresentam maiores escores nas variáveis: "Busco responsabilidades adicionais nos trabalhos que me dão para fazer" e "Eu quero seguir uma carreira como empregado (a) em uma empresa/organização”. A primeira afirmação indica grande grau de compromisso em relação às atividades que se propõe a desenvolver e a segunda mostra que sua preferência está em trabalhar numa organização já estabelecida ao invés de assumir as inúmeras responsabilidades e riscos envolvidos na aberta e manutenção de um negócio próprio.

Em relação aos alagoanos, constata-se que apenas no indicador "Eu tenho maturidade mental (psicológica) para começar a ser um (a) empreendedor (a)” o escore médio foi superior aos demais. Apesar dos níveis educacionais baixos e da falta de qualificação profissional 


\section{A METODOLOGIA DE KRISTIANSEN E INDARTI PARA IDENTIFICAR INTENÇÃO EMPREENDEDORA EM ESTUDANTES DE ENSINO SUPERIOR: COMPARANDO RESULTADOS OBTIDOS NA NORUEGA, INDONÉSIA E ALAGOAS.}

enfrentado pela população local somado ao conhecimento de que mais de $60 \%$ das micro e pequenas empresas no Brasil não sobrevivem aos quatro primeiros anos de vida (SEBRAE, 2004) e de que os empreendedores locais não possuem conhecimentos significativos sobre ferramentas de gestão (NASCIMENTO; DANTAS; MILITO, 2008), ainda assim, os estudantes acreditam que estão preparados para gerir seu próprio negócio.

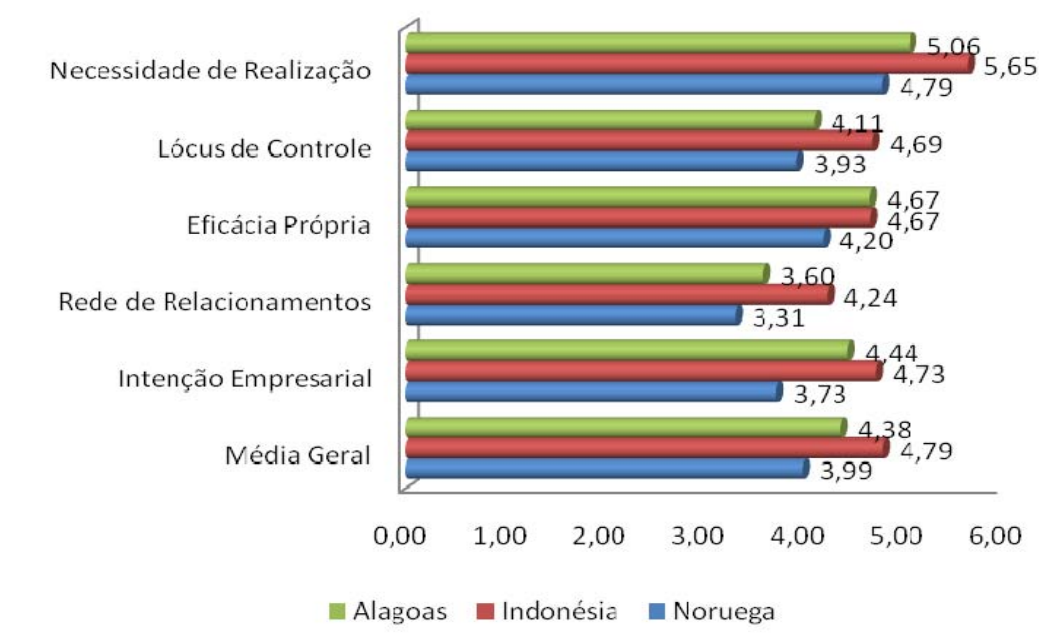

FIGURA 2 - Comparação de escores médios

Fonte: Adaptado de KRISTIANSEN; INDARTI (2004); Dados da pesquisa

Foi possível verificar que as características empreendedoras em análise se apresentam com maior intensidade nos indonésios em todos os constructos, seguido pelos alagoanos e noruegueses. Como a Indonésia não é um dos países presentes nos estudos do GEM não é possível comparar esses resultados com o ranking divulgado pela instituição em 2008. No entanto, se levarmos em conta apenas Alagoas e a Noruega, verifica-se que os resultados encontrados nessa pesquisa se assemelham com os do GEM (2008) onde o Brasil aparece em nono lugar no ranking de empreendedores inicias e a Noruega apenas na vigésima quarta colocação do mesmo ranking.

\begin{tabular}{|c|c|c|c|c|c|c|c|}
\hline \multirow{2}{*}{ Público } & \multirow{2}{*}{ Testes } & \multirow{2}{*}{ Gênero } & \multicolumn{5}{|c|}{ Constructos } \\
\hline & & & NACH & LOC & SELFEFF & INSREAD & INTENT \\
\hline \multirow{5}{*}{$\begin{array}{l}\text { Noruegueses } \\
\qquad(n=121)\end{array}$} & \multirow{2}{*}{ Média } & Mulheres & 4,67 & 5,06 & 3,84 & 3,13 & 2,97 \\
\hline & & Homens & 4,87 & 4,99 & 4,41 & 3,43 & 3,08 \\
\hline & \multirow{2}{*}{ Desvio } & Mulheres & 0,84 & 1,15 & 1,16 & 1,14 & 0,97 \\
\hline & & Homens & 0,82 & 1,22 & 1,17 & 1,21 & 1,24 \\
\hline & \multicolumn{2}{|c|}{ t-test } & $-1,27$ & $-0,06$ & $-2,56^{*}$ & $-1,33$ & $-1,51$ \\
\hline \multirow{5}{*}{$\begin{array}{l}\text { Indonésios } \\
(\mathrm{n}=130)\end{array}$} & \multirow{2}{*}{ Média } & Mulheres & 5,57 & 5,51 & 4,21 & 3,98 & 4,24 \\
\hline & & Homens & 5,55 & 5,70 & 5,15 & 4,50 & 4,69 \\
\hline & \multirow{2}{*}{ Desvio } & Mulheres & 0,84 & 0,94 & 1,10 & 1,04 & 1,30 \\
\hline & & Homens & 0,81 & 0,80 & 1,22 & 1,35 & 1,45 \\
\hline & \multicolumn{2}{|c|}{$t$-test } & 0,09 & $-1,27$ & $-4,60 * *$ & $-2,44^{*}$ & $-1,84$ \\
\hline \multirow{2}{*}{$\begin{array}{l}\text { Alagoanos } \\
(n=339)\end{array}$} & \multirow{2}{*}{ Média } & Mulheres & 5,12 & 5,07 & 4,70 & 3,43 & 4,59 \\
\hline & & Homens & 5,00 & 4,99 & 4,63 & 3,78 & 4,61 \\
\hline
\end{tabular}


THIAGO CAVALCANTE NASCIMENTO

PAULO DA CRUZ FREIRE DOS SANTOS

ANTONIO GIL DA COSTA JUNIOR
ANDERSON DE BARROS DANTAS

MANOEL VERAS

\begin{tabular}{|c|c|l|c|c|c|c|c|}
\multirow{3}{*}{ Desvio } & Mulheres & 0,88 & 0,83 & 1,40 & 1,36 & 1,42 \\
\cline { 2 - 8 } & Homens & 0,86 & 0,95 & 1,40 & 1,48 & 1,49 \\
\cline { 2 - 8 } & \multicolumn{2}{|c|}{$t$-test } & 1,34 & 0,9 & 0,47 & $-2,22 *$ & $-0,11$ \\
\hline
\end{tabular}

Notas: ${ }^{*} \mathrm{p}<0,05,{ }^{* *} \mathrm{p}<0,01$

NACH: Need for Achievement, LOC: Locus of Control, SELFEFF: Self-efficacy, INSREAD: Instrumental Readiness, INTENT: Entrepreneurial Intention

QUADRO 04 - Comparação de Médias por Gênero

Fonte: KRISTIANSEN; INDARTI (2004); Dados da pesquisa

Têm-se a partir do quadro 4 o início dos testes relacionados às hipóteses do estudo de Kristiansen e Indarti (2004). A primeira hipótese pressupõe que fatores demográficos e o contexto individual, como a idade, sexo, educação e experiência profissional têm influência na intenção empresarial. Verifica-se, segundo o t-test, que não existem diferenças significativas em nenhum dos países em relação ao gênero dos entrevistados e sua intenção empresarial.

Também foi possível verificar que não existem diferenças significativas em relação à idade e à intenção empreendedora. Este resultado é condizente com os encontrados por Kristiansen e Indarti (2004). Em relação ao contexto educacional, verifica-se em Kristiansen e Indarti (2004) que na Indonésia existe uma diferença significativa entre os alunos que cursam disciplinas de negócios em comparação com os de outras áreas. Em Alagoas foi encontrado o mesmo resultado, com significância em 1\% e a estatística $t$ com valor de 2,70.

Sobre a experiência profissional constatou-se, em relação ao público alagoano, que não existem diferenças significativas entre o estudante ter ou não experiência profissional sobre a intenção empreendedora. Este resultado se assemelha ao dos estudantes noruegueses. (KRISTIANSEN; INDARTI, 2004).

Segundo essas descobertas, e em consonância com o estudo referência para o desenvolvimento deste trabalho, não é possível aceitar a primeira hipótese, uma vez que foi verificado, em Alagoas, que apenas o contexto de formação profissional atua com diferença significativa em relação à intenção empreendedora.

\begin{tabular}{|c|c|c|c|c|c|c|}
\hline \multirow{2}{*}{ Nacionalidade } & \multirow{2}{*}{ Variáveis } & \multicolumn{5}{|c|}{ Variáveis } \\
\hline & & NACH & LOC & SELEFF & INSREAD & INTENT \\
\hline \multirow{5}{*}{$\begin{array}{c}\text { Noruegueses } \\
(\mathbf{n}=121)\end{array}$} & NACH & & & & & \\
\hline & LOC & $0,204^{*}$ & & & & \\
\hline & SELEFF & $0,339 * *$ & 0,095 & & & \\
\hline & INSREAD & $0,346^{* *}$ & $-0,059$ & $0,548 * *$ & & \\
\hline & INTENT & $0,195^{*}$ & $-0,068$ & $0,386^{* *}$ & $0,433^{* *}$ & \\
\hline \multirow[b]{2}{*}{ Nacionalidade } & \multirow[b]{2}{*}{ Variáveis } & \multicolumn{5}{|c|}{ Variáveis } \\
\hline & & NACH & LOC & SELEFF & INSREAD & INTENT \\
\hline \multirow{3}{*}{$\begin{array}{c}\text { Indonésios } \\
(\mathbf{n}=130)\end{array}$} & NACH & & & & & \\
\hline & LOC & $0,335^{* *}$ & & & & \\
\hline & SELEFF & $0,305^{* *}$ & $0,212 *$ & & & \\
\hline
\end{tabular}

Revista de Negócios, ISSN 1980-4431, Blumenau, v15, n.3, 67- 86, Julho/Setembro 2010. 


\section{A METODOLOGIA DE KRISTIANSEN E INDARTI PARA IDENTIFICAR INTENÇÃO EMPREENDEDORA EM ESTUDANTES DE ENSINO SUPERIOR: COMPARANDO RESULTADOS OBTIDOS NA NORUEGA, INDONÉSIA E ALAGOAS.}

\begin{tabular}{|c|c|c|c|c|c|c|}
\hline & INSREAD & 0,172 & 0,139 & $0,594 * *$ & & \\
\hline & INTENT & 0,075 & $0,207^{*}$ & $0,457 * *$ & $0,406^{* *}$ & \\
\hline & & & & Variávei & & \\
\hline Nacionalidade & Variaveis & NACH & LOC & SELEFF & INSREAD & INTENT \\
\hline & NACH & & & & & \\
\hline & LOC & $0,129 *$ & & & & \\
\hline Alagoanos & SELEFF & $0,309 * *$ & 0,102 & & & \\
\hline & INSREAD & $0,220 * *$ & 0,028 & $0,473 * *$ & & \\
\hline & INTENT & $0,167 * *$ & $0,141^{* *}$ & $0,367 * *$ & $0,314 * *$ & \\
\hline
\end{tabular}

Notas: ${ }^{*} \mathrm{p}<0,05, * * \mathrm{p}<0,01$

NACH: Need for Achievement, LOC: Locus of Control, SELFEFF: Self-efficacy, INSREAD: Instrumental Readiness, INTENT: Entrepreneurial Intention

QUADRO 05 - Coeficiente de Correlação de Pearson

Fonte: KRISTIANSEN; INDARTI (2004); Dados da pesquisa

Em relação aos testes de correlação de Pearson, verificou-se que apenas os estudantes alagoanos obtiveram correlações significativas dos constructos necessidade de realização, lócus de controle, eficácia própria e busca por informações em relação à intenção empresarial. Cabe salientar que a significância nestas situações foi representativa ao nível de $1 \%$.

Outro resultado de destaque apresentado neste quadro diz respeito às maiores correlações encontradas. É possível verificar que no estudo de Kristiansen e Indarti (2004) os constructos relacionados à busca por informações e eficácia própria apresentam maiores correlações em ambos os países. Após a pesquisa em Alagoas, verificou-se a mesma tendência, ou seja, maior carga de correlação entre os mesmos fatores do estudo utilizado como base.

\begin{tabular}{|l|c|c|c|c|}
\hline Variáveis & \multirow{2}{*}{ Testes } & $\begin{array}{c}\text { Noruegueses } \\
(\mathbf{n}=\mathbf{1 2 1})\end{array}$ & $\begin{array}{c}\text { Indonésios } \\
(\mathbf{n}=\mathbf{1 3 0})\end{array}$ & $\begin{array}{c}\text { Alagoanos } \\
(\mathbf{n}=\mathbf{3 3 9})\end{array}$ \\
\cline { 1 - 3 } NACH & \multirow{3}{*}{ B } & 0,034 & $-0,112$ & 0,054 \\
\cline { 4 - 5 } LOC & $-0,079$ & 0,145 & $0,172^{*}$ \\
\cline { 4 - 5 } SELFEFF & & $0,219^{*}$ & $0,340^{*}$ & $0,271^{* *}$ \\
\cline { 3 - 5 } INSREAD & $0,297^{* *}$ & $0,203^{* *}$ & $0,183^{* *}$ \\
\hline \multicolumn{2}{|c|}{$\mathbf{R}^{2}$} & 0,225 & 0,259 & 0,416 \\
\hline \multicolumn{2}{|c|}{$\mathbf{R}^{2}$ ajustado } & 0,198 & 0,236 & 0,163 \\
\hline \multicolumn{2}{|c|}{$\mathbf{F}$} & $8,424^{*}$ & $10,935^{* *}$ & $17,432^{* *}$ \\
\hline
\end{tabular}

Notas: ${ }^{*} \mathrm{p}<0,05,{ }^{* *} \mathrm{p}<0,01$

NACH: Need for Achievement, LOC: Locus of Control, SELFEFF: Selfefficacy, INSREAD: Instrumental Readiness, INTENT: Entrepreneurial Intention QUADRO 06 - Coeficientes de Regressão

Fonte: KRISTIANSEN; INDARTI (2004); Dados da pesquisa

Em relação à segunda hipótese do modelo de pesquisa $\left(\mathrm{H}_{2}\right.$ - Necessidade de realização alta tem um impacto positivo na intenção empresarial), verificou-se que em relação 
THIAGO CAVALCANTE NASCIMENTO

PAULO DA CRUZ FREIRE DOS SANTOS

ANTONIO GIL DA COSTA JUNIOR
ANDERSON DE BARROS DANTAS

MANOEL VERAS

aos estudantes alagoanos não é possível detectar que a necessidade de realização exerce impacto significativo sobre a intenção empresarial. De acordo com esta constatação não é possível aceitar a segunda hipótese do estudo, da mesma forma que Kristiansen e Indarti (2004) em seu estudo.

No que concerne à terceira hipótese $\left(\mathrm{H}_{3}\right.$ - Altas pontuações referentes a lócus de controle são correlacionadas positivamente com intenção empresarial), encontrou-se uma realidade diferente do que foi constatado por Kristiansen e Indarti (2004). Segundo os dados, é possível dizer com um nível $\mathrm{p}<0,05$ que altas pontuações referentes a lócus de controle influenciam positivamente na intenção empresarial dos estudantes alagoanos. Isso nos levar a aceitar a hipótese.

A quarta hipótese $\left(\mathrm{H}_{4}-\right.$ Altas pontuações referentes à auto eficácia são correlacionadas positivamente com intenção empresarial) foi significante na pesquisa de Kristiansen e Indarti (2004) e em Alagoas. Neste último, com $\mathrm{p}<0,01$, ou seja, nível de significância mais representativo do que na pesquisa que deu origem a este estudo. Desta forma é possível aceitar a hipótese de que a auto eficácia exerce influência significativa na intenção empresarial.

A quinta e última hipótese do estudo $\left(\mathrm{H}_{5}\right.$ - Busca por informação é um prognóstico significativamente positivo da intenção empresarial) também pôde ser aceita, com nível de significância ao nível de 1\% nos três países.

Em relação aos pressupostos do modelo de regressão, detectou-se através do VIF e índice Tolerance verificou-se a presença de multicolineariedade em um nível aceitável. Por meio do teste de Durbin-Watson foi possível verificar ausência de auto correlação serial dos resíduos. O pressuposto de normalidade na distribuição dos resíduos também foi aprovado por meio do teste de Kolmogorov-Smirnov. O último pressuposto analisado foi o de homocedasticidade por meio do teste de Pesarán-Pesarán, constatando-se que os resíduos são homoscedásticos.

\section{CONSIDERAÇÕES FINAIS}

Este estudo teve por objetivo avaliar, em Alagoas, a metodologia desenvolvida por Kristiansen e Indarti (2004) em estudos na Noruega e Indonésia, através de uma comparação de seus resultados com estudantes universitários alagoanos.

Os resultados iniciais sobre caracterização do perfil dos entrevistados não apresentam grandes diferenças entre os estudantes alagoanos em relação aos da Noruega e Indonésia. No entanto, o nível de experiência profissional dos noruegueses é algo de destaque quando se compara com a realidade alagoana. No entanto, não foram constatadas diferenças significativas de médias em relação às características empreendedoras. Isto enfraquece o posicionamento de teóricos que defendem que a experiência profissional é fator determinante para o espírito empreendedor.

De forma geral, o instrumento demonstrou adaptabilidade à realidade local, uma vez que o comportamento das variáveis do instrumento de coleta de dados se aproximou significativamente dos resultados obtidos por Kristiansen e Indarti (2004). 
Em relação às hipóteses do estudo, detectou-se um fato que vai em direção oposta à principal corrente teórica sobre a abordagem comportamental, ou seja, as baseadas nos estudos de McClelland (1961), sem deixar de excluir este estudo.

Uma destas hipóteses estava direcionada a verificar a influência de fatores sóciodemográficos na intenção empresarial, enquanto todas as outras se relacionavam a elementos comportamentais (necessidade de realização, lócus de controle e eficácia própria) e contextuais (busca por informações). Em Alagoas, a única hipótese sobre elementos comportamentais que não pôde ser confirmada foi a seguinte: "Necessidade de realização alta tem um impacto positivo na intenção empresarial”. Vale citar que está hipótese também foi rejeitada no estudo de Kristiansen e Indarti (2004) em relação a ambos os países pesquisados pelos autores.

Ainda foi possível verificar que o comportamento empreendedor dos estudantes universitários alagoanos se aproxima muito dos níveis apresentados pelos indonésios, e que os fatores sócio-demográficos se distribuíram de forma semelhante. Como a pesquisa não é cabível de generalização, uma vez que a quantidade de IES estudada representa uma parcela muito pequena da população, não é possível afirmar que a distribuição de tais características ocorra no restante do país de forma semelhante, tão pouco que as características comportamentais serão as mesmas. No entanto, levanta mais um questionamento, desta vez, relacionado aos fatores culturais e de poder econômico de um país ou região sob o desenvolvimento de características empreendedoras. Até que ponto tais fatores exercem e como exercem influência sob o desenvolvimento destas características?

Há de se salientar que este estudo não teve por objetivo explorar possibilidades que possam ter ocasionado diferenças de percepção entre os estudantes de Alagoas com os dos países envolvidos na pesquisa de Kristiansen e Indarti (2004), uma vez que a base de dados não possibilita ampliar as discussões para esta vertente. Mesmo assim, acredita-se que as principais diferenças entre os grupos ocorrem como uma consequência de padrões sóciodemográficos completamente diferentes entre as localidades em que o instrumento foi aplicado inicialmente e onde os autores deste artigo e reaplicaram. Neste sentido, existe uma série de indicadores econômicos e sociais, bem como fatores culturais que podem afetar a percepção destes alunos quanto ao interesse de abrir negócios ou não.

As principais limitações do estudo recaem sobre a não representatividade da amostra, o que impede que sejam traçadas inferências sobre o público-alvo do estudo e o fato de se ter trabalhado com o teste $t$ de Student de forma inadequada, uma vez que variáveis em escala de likert dificilmente se comportam de acordo com a distribuição normal (pressuposto do teste), mas que foi necessário para que fosse possível comparar os resultados com os de Kristiansen e Indarti (2004).

\section{REFERENCIAS}

ALMEIDA, D. R.; BENEVIDES, T. M. Perfil do micro e pequeno empresário que busca desenvolver a cultura empreendedora: o caso de um município baiano. In: ENCONTRO NACIONAL DA ASSOCIAÇÃO DE PÓS-GRADUAÇÃO E PESQUISA EM ADMINISTRAÇÃO, 29., 2005, Brasília. Anais... Brasília: ANPAD, 2005. 
BARRETO, R. R. et al. Potencial empreendedor: uma comparação sob três metodologias. In: ENCONTRO NACIONAL DE ENGENHARIA DE PRODUÇÃO, 26., 2006, Fortaleza. Anais... Fortaleza: ABEPRO, 2006.

BAUMOL, W. J. Entrepreneuship in economic theory. The American Economic Review, v. 58, n. 2, p. 64-71, 1968.

CÂMARA, S. F. et al. Os empreendedores e as atividades organizacionais: analisando o processo cognitivo e as práticas administrativas em pequenos negócios. In: ENCONTRO NACIONAL DA ASSOCIAÇÃO DE PÓS-GRADUAÇÃO E PESQUISA EM ADMINISTRAÇÃO, 29., 2005, Brasília. Anais... Brasília: ANPAD, 2005.

CANTILLON, R. Essai sur la nature du commerce en général. Londres: Chez Fletcher Gyles dans Holborn, 1755.

CERVO, A. L.; BERVIAN, P. A. Metodologia científica. 5 ed. São Paulo: Prentice Hall, 2002.

CUNHA, J. V. A.; COELHO, A. C. Regressão linear múltipla. In.: CORRAR, L. J.; PAULO, E.; DIAS FILHO, J. M. (Coord.). Análise multivariada para os cursos de administração, ciências contábeis e economia. São Paulo: Atlas, 2007.

DANCEY, C. P. Estatística sem matemática para psicologia. 3 ed. Porto Alegre: Artmed, 2006.

DIAS, E. L. Um estudo comparativo entre empreendedores e intraempreendedores sobre os valores referentes ao trabalho. Florianópolis, 2001. Dissertação (Mestrado em Engenharia de Produção) - Programa de Pós-Graduação em Engenharia de Produção, Universidade Federal de Santa Catarina, Florianópolis, 2001.

DOLABELA, F. Oficina do empreendedor. 2. ed. São Paulo: Cultura, 1999a.

O segredo de Luísa. São Paulo: Cultura, 1999b.

Pedagogia empreendedora. São Paulo: Cultura, 2003.

DORNELAS, J. C. A. Empreendedorismo: transformando idéias em negócios. Rio de Janeiro: Campus, 2001.

DRUCKER, P. F. Inovação e espírito empreendedor (entrepreneurship): prática e princípios. 2. ed. São Paulo: Pioneira, 1987.

DUTRA, I. S.; PREVIDELLI, J. J. Perfil do empreendedor versus mortalidade de empresas: estudo de caso do perfil do micro e pequeno empreendedor. In: ENCONTRO NACIONAL DA ASSOCIAÇÃO DE PÓS-GRADUAÇÃO E PESQUISA EM ADMINISTRAÇÃO, 27., 2003, Atibaia. Anais... Atibaia: ANPAD, 2003.

FELÍCIO JR., J. Learning organization numa instituição de ensino superior: uma proposta empreendedora. Pedro Leopoldo, 2002. 157 p. Dissertação (Mestrado Profissional em Administração) - Fundação Cultural Dr. Pedro Leopoldo, Pedro Leopoldo, 2002. 


\section{A METODOLOGIA DE KRISTIANSEN E INDARTI PARA IDENTIFICAR INTENÇÃO EMPREENDEDORA EM ESTUDANTES DE ENSINO SUPERIOR: COMPARANDO RESULTADOS OBTIDOS NA NORUEGA, INDONÉSIA E ALAGOAS.}

FILION. L. J. et al. Boa idéia! E agora: plano de negócio, o caminho seguro para criar e gerenciar sua empresa. São Paulo: Cultura, 2000.

GEM - Global Entrepreneurship Monitor. Empreendedorismo no Brasil - 2004 - Curitiba 2006.

2008.

. Empreendedorismo no Brasil - 2007 - Curitiba

GUIMARÃES, T. B. C. Análise epistemológica do campo do empreendedorismo. In: ENCONTRO NACIONAL DA ASSOCIAÇÃO DE PÓS-GRADUAÇÃO E PESQUISA EM ADMINISTRAÇÃO, 28., 2004, Curitiba. Anais... Curitiba: ANPAD, 2004.

GRUNDSTEN, H. Entrepreneurial intentions and the entrepreneurial environment: a study of technology-based new venture creation. Helsinki, 2004. Dissertation (Dissertation for the degree of Doctor of Science in Technology) - Department of Industrial Engineering and management, Helsinki University of Technology, Helsinki, 2004.

INSTITUTO BRASILEIRO DE GEOGRAFIA E ESTATÍSTICA. As micro e pequenas empresas comerciais e de serviços. Rio de Janeiro, 2003.

JULIEN, P. A. A theory of local entrepreneurship in the knowledge economy. Massachusetts: Edward Elgar Publishing Limited, 2007.

KRISTIANSEN, S.; INDARTI, N. Etrepreneurial intention among Indonesian and Norwegian students. Journal of Enterprising Culture, v. 12, n. 1, p. 55-78, 2004.

LEIBENSTEIN, H. Entrepreneurship and development. The American Economic Review, v. 58, n. 2, p. 72 - 83. May, 1968.

MALHOTRA, N. Pesquisa de marketing: uma orientação aplicada. 4 ed. Porto Alegre: Bookman, 2006.

MAZZAROL, T. et al. Factors influencing small business start-ups: a comparison with previous research. International Journal of Entrepreneurial Behaviour \& Research. v. 5. n. 2. 1999.

McCLELLAND, D. C. The Achieving Society. Princeton: Van Nostrand, 1961.

NASCIMENTO, T. C.; DANTAS, A. B.; MILITO, C. M. Empreendedorismo e gestão de negócios: análise de uma possível convergência. In: ENCONTRO NACIONAL DA ASSOCIAÇÃO DE PÓS-GRADUAÇÃO E PESQUISA EM ADMINISTRAÇÃO, 32., 2008, Rio de Janeiro. Anais... Rio de Janeiro: ANPAD, 2008.

NASCIMENTO JR., O. R.; DANTAS, A. B.; SANTOS, P. C. F. Prospecção do potencial empreendedor: validação de uma proposta metodológica. In: ENCONTRO NACIONAL DA ASSOCIAÇÃO DE PÓS-GRADUAÇÃO E PESQUISA EM ADMINISTRAÇÃO, 29., 2005, Brasília. Anais... Brasília: ANPAD, 2005.

PAIVA JR., F. G.; LEÃO, A. L. M.; MELLO, S. C. B. Competências empreendedoras em comportamentos de dirigentes de êxito socialmente reconhecido. In: ENCONTRO 
NACIONAL DA ASSOCIAÇÃO DE PÓS-GRADUAÇÃO E PESQUISA EM ADMINISTRAÇÃO, 27., 2003, Atibaia. Anais... Atibaia: ANPAD, 2003.

PEREIRA, C. E. C.; COSTA, A. C. S. Potencial empreendedor dos alunos do ensino médio em escolas públicas e privadas de Maceió. In: ENCONTRO NACIONAL DE ENGENHARIA DE PRODUÇÃO, 26., 2006, Fortaleza. Anais... Fortaleza: ABEPRO, 2006.

RODRIGUES, A.; PAULO. E. Introdução à análise multivariada. In.: CORRAR, L. J.; PAULO, E.; DIAS FILHO, J. M. (Coord.). Análise multivariada para os cursos de administração, ciências contábeis e economia. São Paulo: Atlas, 2007.

SAY, Jean-Baptiste. A treatise on political economy. Philadelphia: Grigg \& Elliott, 1832.

SERVIÇO BRASILEIRO DE APOIO ÀS MICRO E PEQUENAS EMPRESAS. Fatores condicionantes e taxa de mortalidade de empresas no Brasil. Brasília: SEBRAE, 2004.

SCHUMPETER, J. A. The theory of economic development. Oxford: Oxford University Press, 1934.

UNCTAD - UNITED NATIONS CONFERENCE ON TRADE AND DEVELOPMENT. Entrepreneurship and economic development: the empretec showcase. Geneva, 2004. 